\title{
Leukaemia mortality among relatives of cystic fibrosis patients
}

\author{
L N Al-Jader, R R West, J A Holmes, L Meredith, M C Goodchild, P S Harper
}

\begin{abstract}
A total of 219 families of patients with cystic fibrosis living in Wales were studied for the occurrence of other diseases and for cause of death, and the findings in relation to leukaemia are reported. There were eight deaths due to leukaemia, five of the myeloid type, in first and second degree relatives; this is significantly more than the expected on the basis of national age specific mortality rates. In comparison, mortality among siblings, parents, aunts and uncles, and grandparents from all causes was within the expected. Screening the five patients with myeloid leukaemia for the delta F508 mutation showed that four were carriers of this mutation. It is concluded that carriers of the delta F508 mutation may have an increased risk of developing acute myeloid leukaemia. This could happen through the direct effect of the cystic fibrosis gene itself, or through its influence on another gene, such as the met oncogene, or gene(s) involved in granulocyte function on the long arm of chromosome 7.
\end{abstract}

Cystic fibrosis is inherited as an autosomal recessive disease for which the most common gene mutation, delta F508, has been defined on $7 \mathrm{q} 31 .^{1}$ In view of the relative frequency of cystic fibrosis, ${ }^{2}$ its variable clinical features, and the multisystem involvement, an association with other diseases might be expected.

As part of a systematic clinical and molecular genetic study of this disorder in Wales a specific inquiry was made about the incidence of various diseases in patients and their relatives. In 1989, we published a preliminary report on this survey showing an increased mortality from leukaemia among first and second degree relatives of 130 families of patients with cystic fibrosis living in Wales. ${ }^{3}$ Since then 89 other families have been studied. We report here the principal findings of the whole survey.

\section{Patients and methods}

A genetic survey of families of patients with cystic fibrosis in Wales was carried out over a period of 28 months (June 1987-September 1989). Altogether 219 families of 230 patients, representing $75 \%$ of all patients with cystic fibrosis living in different parts of Wales, were studied as part of a formal genetic study, set up mainly in order to provide genetic counselling. No bias was exercised in the selection of patients for this study; all were seen during the usual cystic fibrosis clinic sessions when they attended for routine clinical follow up. The diagnosis of cystic fibrosis had been made by the paediatrician, based on typical clinical presentation and features, family history in some cases, and at least one positive sweat test. Multigeneration pedigree and detailed family history were obtained, including age if alive on January 1988, age at death and cause of death (if known), or age at 'lost to follow up'.

Data on first and second degree relatives were included and grouped as: siblings, half siblings, parents, aunts and uncles, and grandparents.

The expected and observed numbers of deaths were compared for leukaemia of all types, myeloid leukaemia, and all causes combined. The expected numbers of deaths were obtained by multiplying for each group person years at risk by age $(0-4,5-14,15-24$, etc) with the age specific mortality for England and Wales (1979-88) for leukaemia, myeloid leukaemia, and all causes combined. ${ }^{4}$ Parents and grandparents of patients with cystic fibrosis had to have survived to reproductive age and the generation intervals for these families average 24.4 years: accordingly person years at risk and expected mortality for parents and grandparents have been estimated from age 24 . Siblings, aunts and uncles, however, were at risk of infant and early childhood death, and older aunts and uncles were at risk of higher death rates earlier in the century. Accordingly person years at risk of death and the expected mortality for those aged $<5$ years were estimated on a cohort of birth basis (in decades). The observed numbers of deaths were compared with the expected, using the Poisson probability distribution.

Carrier status of the eight relatives who died of leukaemia was sought; DNA was extracted from bone marrow slides of three relatives. DNA was also extracted from all relevant members of these families, and they were screened for the most common cystic fibrosis mutation in Britain, delta F508, by amplification of genomic DNA by the polymerase chain reaction. ${ }^{5}$ Separation of polymerase chain reaction products was by polyacrylamide gel electrophoresis allowing identification of carriers.

All cases of leukaemia were verified from the original haematological studies.

\section{Results}

The families of 230 patients with cystic fibrosis living in Wales were interviewed by LNAJ, identifying 438 parents, 227 siblings, 96 half siblings, 1252 aunts and uncles, and 869 grandparents. 
Eight first and second degree relatives of patients with cystic fibrosis had died of leukaemia: five with acute myeloid leukaemia, two with acute lymphoblastic leukaemia, and one with chronic lymphatic leukaemia. A grandfather suffering from chronic lymphatic leukaemia, who was alive, was not included in the study. Information on age (alive, lost to follow up, or dead) was incomplete for $7 \%$ of aunts and uncles and $11 \%$ of grandparents; these were assigned according to the age distribution of the appropriate group. The expected number of leukaemia deaths for all relatives combined was (3.1) compared with the observed number (8) using the Poisson probability test as shown in table $1(\mathrm{p}<0.02)$.

Table 1 The expected and observed number of leukaemia deaths among first and second degree relatives of patients with cystic fibrosis

\begin{tabular}{lcll}
\hline Relationship & $\begin{array}{l}\text { No at } \\
\text { risk }\end{array}$ & $\begin{array}{l}\text { Expectedf } \\
\text { deaths }\end{array}$ & $\begin{array}{l}\text { Observed } \\
\text { deaths }\end{array}$ \\
\hline Sibling & 227 & 0.06 & 0 \\
Half sibling & 96 & 0.02 & 1 \\
Parentt & 438 & $0.15 \ddagger$ & 2 \\
Aunt or uncle & 1252 & 0.98 & 2 \\
Grandparent & 869 & $1.87 \ddagger$ & 3 \\
\hline Total & 2882 & $3^{*} 1^{*}$ & $8^{*}$ \\
\hline
\end{tabular}

\section{${ }^{*} \mathrm{p}<0.02$.}

tOn the basis of age specific death rates for England and Wales 1979-88.

†For parents and grandparents, person years at risk and expected mortality has been determined from age 24

Table 2 The expected and observed number of deaths from acute myeloid leukaemia among first and second degree relatives of patients with cystic fibrosis

\begin{tabular}{|c|c|c|c|}
\hline Relationship & $\begin{array}{l}\text { No at } \\
\text { risk }\end{array}$ & $\begin{array}{l}\text { Expectedt } \\
\text { deaths }\end{array}$ & $\begin{array}{l}\text { Observed } \\
\text { deaths }\end{array}$ \\
\hline $\begin{array}{l}\text { Sibling } \\
\text { Half sibling } \\
\text { Parent } \ddagger \\
\text { Aunt or uncle } \\
\text { Grandparent } \ddagger\end{array}$ & $\begin{array}{r}227 \\
96 \\
438 \\
1252 \\
869\end{array}$ & $\begin{array}{l}0.01 \\
0 \cdot 01 \\
0 \cdot 10 \ddagger \\
0 \cdot 47 \\
1 \cdot 13 \ddagger\end{array}$ & $\begin{array}{l}0 \\
0 \\
2 \\
1 \\
2\end{array}$ \\
\hline Total & 2882 & $1 \cdot 7^{*}$ & $5^{*}$ \\
\hline
\end{tabular}

The expected numbers of deaths from myeloid leukaemia among relatives of patients with cystic fibrosis were also calculated as shown in table 2. The expected number of deaths $(1 \cdot 7)$ was compared with the observed number (5) using the Poisson probability distribution $(p<0.05)$. These figures for both leukaemia and myeloid leukaemia become slightly more significant if account is taken of the standardised mortality ratio for leukaemia in Wales (0.93) compared with England and Wales $(1 \cdot 00)$ during the reference period.

Table 3 sets out details of the eight relatives who died of leukaemia in our survey. Case 5 had myelodysplastic syndrome which progressed to acute myeloid leukaemia before his death Patients were from different families, apart from cases 3 and 4, who were father and daughter. Screening the five patients with acute myeloid leukaemia for the delta F508 showed that four were carriers of this mutation (three by polymerase chain reaction amplification of bone marrow specimens and slides and one by inference from the rest of the family). Though we could not confirm mutational status in the fifth patient (case 4), either by inference or actual screening of haematological specimens, he had a $50 \%$ chance of carrying the same mutation. Chromosomal study was done from bone marrow aspirate on three of the patients with acute myeloid leukaemia.

The observed mortality from all causes was within the expected for siblings, parents, aunts and uncles, and grandparents (table 4).

Table 4 All cause mortality in first and second degree relatives of patients with cystic fibrosis

\begin{tabular}{lccc}
\hline Relationship & $\begin{array}{l}\text { No at } \\
\text { risk }\end{array}$ & $\begin{array}{l}\text { Expected } \\
\text { deaths }\end{array}$ & $\begin{array}{l}\text { Observed } \\
\text { deaths }\end{array}$ \\
\hline Sibling & 227 & $3 \cdot 7$ & 7 \\
Half sibling & 96 & $1 \cdot 4$ & 4 \\
Parent & 438 & $8 \cdot 9^{*}$ & 10 \\
Aunt or unclet & 1252 & 108 & 92 \\
Grandparent* & 869 & $247^{*}$ & 264 \\
\hline
\end{tabular}

${ }^{*}$ For parents and grandparents, person years at risk and expected mortality have been determined from age 24 .

tFor aunts and uncles, early mortality (age $<5$ years) has been determined by decade cohorts.

On the basis of age specific death rates for England and Wale 1979-88.

Table 3 Individual details of the leukaemia cases

\begin{tabular}{|c|c|c|c|c|c|c|}
\hline $\begin{array}{l}\overline{\text { Case }} \\
\text { No }\end{array}$ & Relationship & $\begin{array}{l}\text { Age } \\
\text { at } \\
\text { death }\end{array}$ & $\begin{array}{l}\text { Year of } \\
\text { death }\end{array}$ & $\begin{array}{l}\text { Presence (+) or } \\
\text { absence }(-) \text { of } \\
\text { delta } F 508 \\
\text { mutation }\end{array}$ & Karyotype ${ }^{*}$ & Diagnosis \\
\hline 1 & Father & 42 & 1981 & + & XY 46 & Acute myeloid \\
\hline 2 & Mother & 37 & 1986 & + & XX 46 & Acute myeloid \\
\hline 3 & Aunt & 55 & 1975 & $(+) t$ & ND & Acute myeloid \\
\hline 4 & Grandfather & 73 & 1954 & $?$ & ND & Acute myeloid \\
\hline 5 & Grandfather & 78 & 1988 & + & X 45 & Acute myeloid \\
\hline 6 & Uncle & 3 & 1967 & $?$ & ND & $\begin{array}{l}\text { Acute lymphoblastic } \\
\text { leukaemia }\end{array}$ \\
\hline 7 & Half sister & 2 & 1987 & - & $\ddagger$ & $\begin{array}{l}\text { Acute lymphoblastic } \\
\text { leukaemia }\end{array}$ \\
\hline 8 & Grandfather & 75 & 1975 & + & ND & $\begin{array}{l}\text { Chronic lymphatic } \\
\text { leukaemia }\end{array}$ \\
\hline
\end{tabular}

* Karyotype done once at diagnosis.

$t(+)$ Carrier status by inference.
$\neq 46 \times X / 55 \times X,+4,+6,+8,+10,+14,+17,+18,+21,+21$

$+46 \times X / 55 X X,+4,+6,+8,+10,+14,+17,+$
$? 50 \%$ risk of carrying the delta F508 mutation.

ND, not done. 


\section{Discussion}

Our previous preliminary report showed an excess mortality from leukaemia among first and second degree relatives of patients with cystic fibrosis and the excess was most striking for parents, who are obligatory carriers of the cystic fibrosis gene. ${ }^{3}$ The present report on $75 \%$ of the Welsh families with a patient with cystic fibrosis still shows an excess mortality from leukaemia and most particularly that the excess was of the myeloid type.

Although the survey has revealed a further living leukaemia case, he is not included in this study as the analysis is of mortality. We also have confirmed that four out of the five patients with acute myeloid leukaemia were carrying the delta F508 mutation.

As this survey was based on a genetic counselling service for families and the analysis is primarily of relatives of living patients with cystic fibrosis, mortality among the patients themselves has not been included in the analysis composition. Although no leukaemia deaths were found among deceased patients with cystic fibrosis in our survey, leukaemia has been reported previously in patients with cystic fibrosis: four children and two adults, three of whom had acute myeloid leukaemia, though acute lymphoblastic leukaemia would be expected to predominate in their age group. ${ }^{6}$ As infection remains a major cause of death in patients with cystic fibrosis and serious infection is not unexpected, Biggs and colleagues questioned whether death may occur in early phase of leukaemia, and compared the previous lack of recognition of acute leukaemia in patients with cystic fibrosis to the under-reported incidence of leukaemia in general before the antibiotic era. ${ }^{6}$ They also discussed whether the prolonged survival of patients with cystic fibrosis would result in recognition of a predisposition to leukaemia.

Monosomy for chromosome 7 and partial deletion of the chromosome 7 long arm (7q-) are among the common recurring clonal chromosome abnormalities observed in bone marrow cells in patients with acute nonlymphocytic leukaemia or myelodysplastic syndrome. ${ }^{7}$ The loss of all or part of chromosome 7 long arm has seen associated with a granulocyte chemotaxis defect, a susceptibility to infections, a rapid progression of the disease, and a poor response to treatment. ${ }^{8}$ Patients with a $7 q$ - chromosome had a deletion breakpoint in a narrow region between the erythropoietin and plasminogen activator type 1 genes on either side of the cystic fibrosis gene locus. ${ }^{7}$ Bone marrow monosomy 7 in children has been associated with a distinct myeloproliferative syndrome that usually evolves into acute myeloid leukaemia. It also appears that a significant incidence (up to $30 \%$ ) of monosomy 7 in children may be familial. ${ }^{9}$

Met oncogene mapped to band $7 q 21-31$, is closely linked to the cystic fibrosis gene. ${ }^{10}$ Its activation through a DNA rearrangement resulting in the fusion of a translocated promoter region locus on chromosome 1 to the
5 region of sequences derived from the met locus on chromosome 7 , is known to occur in vitro when human osteogenic sarcoma cell line is treated with a chemical carcinogen ( $\mathrm{N}$-methyl$\mathrm{N}$-nitro-N-nitrosoguanidine). ${ }^{11}$ Met is also amplified and overexpressed in the human gastric tumour cell line, ${ }^{12}$ adenocarcinoma of the pancreas, and adenocarcinoma of the colon among a few other non-haemopoietic tumour cell lines tested. ${ }^{13}$ Similarity has been noted in the strucuture of the activated met gene with that of the activated abl gene involved in Philadelphia chromosomal translocation occurring in chronic myeloid leukaemia, ${ }^{13}$ suggesting that these genes encode aberrant tyrosine kinases that do not respond to normal cellular control mechanisms. ${ }^{14}$

We conclude that carriers of the delta F508 mutation in the cystic fibrosis gene may have an increased risk of developing acute myeloid leukaemia. This could be through the direct effect of the gene or gene product itself or through its influence on another gene, such as the met oncogene, or gene(s) involved in granulocyte function on the long arm of chromosome 7. This influence might occur by the somatic loss of a tumour suppressor gene on the homologous chromosome 7 , either through gross chromosomal rearrangements or point mutations.

As a follow up to our study an analysis of all acute myeloid leukaemia patients for frequency of the delta F508 mutation is now being carried out at the University Hospital of Wales. This should give information on whether our findings are of more general relevance outside families affected with cystic fibrosis. We thank Professor A Jacobs, Dr RA Padua, and N Warren of
the department of haematology, University Hospital of Wales, the department of haematology,
Cardiff, for helpful discussions.

1 Kerem B-S, Rommens JM, Buchanan JA, et al. Identification of the CF gene: genetic analysis. Science 1989;245:1073-80.

2 Ryley HC, Deam SA, Williams J, et al. Neonatal screening for cystic fibrosis in Wales and West Midlands: 1 . Evalua726-9.

3 Al-Jader LN, West RR, Goodchild MC, Harper PS. Mortality from leukaemia among relatives of patients with Mortality from leukaemia among rela
cystic fibrosis. $B M \mathcal{F}$ 1989;298:164.

cystic fibrosis. BMF 1989;298: 164 .
4 Office of Population Census and Surveys. Mortality statistics in England and Wales: cause (for years 1979-88). London: England and Wale:
HMSO, 1981-90.

5 McIntosh I, Lorenzo ML, Brock DJH, et al. Frequency of delta F508 mutation on cystic fibrosis chromosomes in the UK. Lancet 1989;ii:1404-5.

6 Biggs B, Vaughan W, Sanger W, Purtilo D. Cystic fibrosis complicated by acute leukaemia. Cancer 1986;57:2441-3.

7 Kere J, Ruutu KA, Davies KA, et al. Chromosome 7 long arm deletion in myeloid disorder: a narrow breakpoint region in 7q22 defined by molecular mapping. Blood 1989; 73:230-4.

8 Ruutu P, Ruutu T, Vuopio P, et al. Defective chemotaxis in monosomy 7. Nature 1977;265:146-7.

9 William L, Carroll MD, Rodman Morgan MS, et al. Childhood bone marrow monosomy 7 syndrome: a familial disorder? $f$ Pediatr 1985;107:578-80.

10 Dean $M$, Park M, Le Beau $M$, et al. The human met oncogene is related to tyrosine kinase oncogenes. Nature 1985;318:385-8.

11 Park M, Dean M, Cooper CS, et al. Mechanism of met oncogene activation. Cell 1986;45:895-904.

12 Giordano S, Ponzetto C, Di Renzo MF, et al. Tyrosine kinase receptor indistinguishable from the c-met protein. Nature 1989;339:155-6.

13 Soman NR, Wogan GN, Rhim JS. TPR-MET oncogenic rearrangement: detection by polymerase chain reaction amplication of the transcript and expression in human tumor cell lines. Proc Natl Acad Sci USA 1990;87:738-42.

14 Tempest PR, Reeve BR, Spurr NK, et al. Activation of the met oncogene in the human MNNG-HOS cell line involves a chromosomal rearrangement. Carcinogenesis 1986;7 2051-7. 